Case Report

\title{
Three Cases of Previous Smokers with Rheumatoid Arthritis Who Did Not Respond to Tumor Necrosis Factor Inhibitors Were Treated Successfully with an Anti-Interleukin-6 Receptor Antibody
}

\author{
Yasuo Iwata \\ Iwata Orthopedics and Rheumatology Clinic, No. 13-5, 1 A Nakasuji 8-Chome, Takarazuka, Hyogo 665-9874, Japan \\ Correspondence should be addressed to Yasuo Iwata; iwataseikei@yahoo.co.jp
}

Received 13 October 2014; Accepted 12 December 2014

Academic Editor: Suleyman Serdar Koca

Copyright (C) 2015 Yasuo Iwata. This is an open access article distributed under the Creative Commons Attribution License, which permits unrestricted use, distribution, and reproduction in any medium, provided the original work is properly cited.

\begin{abstract}
We report three cases of previous smokers who did not respond to TNF inhibitors but who responded successfully to an antiinterleukin-6 receptor antibody (tocilizumab (TCZ)). Case 1 is a 63-year-old woman whose smoking index was 200 and had been complaining of polyarthralgia since 1996. She started treatment with etanercept due to high disease activity, but her DAS28-CRP was 4.2. She was therefore switched to TCZ, which dramatically improved her symptoms; her DAS28-CRP had decreased to 2.1. Case 2 is a 64-year-old man whose smoking index was 1600 and had been complaining of polyarthralgia since 2006. Because his DAS28-CRP score increased over time to 5.9, etanercept and adalimumab were added sequentially, but he showed no response over the course of two years. The patient was therefore switched to TCZ, which dramatically improved his symptoms: his DAS28-CRP decreased to 2.7. Case 3 is a 48-year-old woman whose smoking index was 560 and had been complaining of pain in both knee joints since 2001. She was treated with adalimumab due to high disease activity but showed no response over the course of 1.5 years. The patient was therefore switched to TCZ, and her DAS28-CRP decreased to 1.8. An IL-6 blockade might be suitable for treating these 3 cases of previous smokers.
\end{abstract}

\section{Introduction}

Tumor necrosis factor (TNF) inhibitors represent an important advance in therapy for rheumatoid arthritis (RA). RA patients who smoke, however, are reported to be less likely to respond to treatment with TNF inhibitors [1-4]. This report presents three cases of smokers who did not respond to TNF inhibitors but who responded successfully to an antiinterleukin-6 receptor antibody (tocilizumab [TCZ]).

\section{A Case Report}

Case 1 is a 63-year-old woman whose smoking index was 200 (10 cigarettes/day $\times 20$ years) (Table 1$)$ and had been complaining of polyarthralgia since 1996 . She could not take methotrexate due to the adverse effects of liver dysfunction and hair loss. During treatment for RA, she was able to quit smoking as per our instructions. Two years after her first visit, the lateral tibial condyle of her right knee joint collapsed. As a result, she underwent total knee arthroplasty. She started treatment with the TNF inhibitor etanercept due to high disease activity (Disease Activity Score assessing 28 joints with C-reactive protein [DAS28-CRP] was 4) 1.5 years after cessation of smoking but showed no response. Two years after starting this medication, her DAS28-CRP was 4.2 and her MMP-3 was $405 \mathrm{ng} / \mathrm{mL}$. The patient was therefore switched to TCZ ( $8 \mathrm{mg} / \mathrm{kg}$ monthly), which dramatically improved her symptoms. Six months after switching to TCZ, her DAS28CRP had decreased to less than 2.3 and her MMP-3 had decreased from 405 to less than $59.7 \mathrm{ng} / \mathrm{mL}$ (Figure 1). She has satisfied the Boolean-based definition for over 10 months after the cessation of the TCZ therapy. Recent radiograms of the involved joints show nonprogression.

Case 2 is a 64-year-old man whose smoking index was 1600 (40 cigarettes/day $\times 40$ years) (Table 1$)$ and had been complaining of polyarthralgia since 2006 . He did not respond 
TABLE 1: Characteristics of patients.

\begin{tabular}{|c|c|c|c|}
\hline & Case 1 & Case 2 & Case 3 \\
\hline Sex & Female & Male & Female \\
\hline Age (years) & 63 & 64 & 48 \\
\hline Disease duration (years) & 12 & 6 & 8 \\
\hline Smoking index & $\begin{array}{c}200 \\
(10 \text { cigarettes/day } \times 20 \text { years }) \\
\end{array}$ & $\begin{array}{c}1600 \\
(40 \text { cigarettes/day } \times 40 \text { years })\end{array}$ & $\begin{array}{c}560 \\
(20 \text { cigarettes/day } \times 28 \text { years }) \\
\end{array}$ \\
\hline $\begin{array}{l}2010 \text { ACR/EULAR classification } \\
\text { criteria }\end{array}$ & Satisfied & Satisfied & Satisfied \\
\hline Laboratory results & $\begin{array}{c}\text { RF } 73.8 \mathrm{U} / \mathrm{mL} \\
\text { ACPA } 4.4 \mathrm{U} / \mathrm{mL} \\
\text { CRP } 2.9 \mathrm{mg} / \mathrm{dL} \\
\text { WBC } 11500 / \mu \mathrm{L} \\
\text { MMP-3 } 698.7 \mathrm{ng} / \mathrm{mL} \\
\text { Platelet } 37.1 \times 10^{4} / \mu \mathrm{L} \\
\end{array}$ & $\begin{array}{c}\text { RF } 60.0 \mathrm{U} / \mathrm{mL} \\
\text { ACPA } 150.0 \mathrm{U} / \mathrm{mL} \\
\text { CRP } 1.5 \mathrm{mg} / \mathrm{dL} \\
\text { WBC } 8600 / \mu \mathrm{L} \\
\text { MMP-3 } 148.1 \mathrm{ng} / \mathrm{mL} \\
\text { Platelet } 35.0 \times 10^{4} / \mu \mathrm{L}\end{array}$ & $\begin{array}{c}\text { RF } 26.0 \mathrm{U} / \mathrm{mL} \\
\text { ACPA } 128.6 \mathrm{U} / \mathrm{mL} \\
\text { CRP } 0.07 \mathrm{mg} / \mathrm{dL} \\
\text { WBC } 12400 / \mu \mathrm{L} \\
\text { MMP-3 } 179.5 \mathrm{ng} / \mathrm{mL} \\
\text { Platelet } 42.1 \times 10^{4} / \mu \mathrm{L}\end{array}$ \\
\hline $\begin{array}{l}\text { Steinbrocker's roentgenographic } \\
\text { classification }\end{array}$ & Stage IV & Stage III & Stage III \\
\hline $\begin{array}{l}\text { Functional status according to } \\
\text { Steinbrocker's revised criteria }\end{array}$ & Class II & Class II & Class II \\
\hline
\end{tabular}

Steinbrocker's revised criteria

Etanercept 25-50 mg/week (13)

Adalimumab $40 \mathrm{mg} / 2$ weeks (4)

Methotrexate $8 \mathrm{mg} /$ week (72)

Prednisolone $5 \mathrm{mg} /$ day (36)

Bucillamine 200 mg/day (48)

Gold sodium thiomalate $10 \mathrm{mg} /$ week (24)

Mizoribine 150 mg/day (18)
Adalimumab $40 \mathrm{mg} / 2$ weeks (4)

Methotrexate $6 \mathrm{mg} /$ week (72)

Prednisolone $9 \mathrm{mg} /$ day (36)

Salazosulfapyridine $1000 \mathrm{mg} /$ day

(6)

Mizoribine $200 \mathrm{mg} /$ day (18)

Time (months) to remission of

11

16

1

(DAS28-CRP <2.3)

RF: rheumatoid factor; ACPA: anti-cyclic citrullinated peptide antibody; CRP: C-reactive protein; WBC: white blood cell count; MMP-3: matrix metalloproteinase-3.

to a combination of methotrexate ( $8 \mathrm{mg} /$ week), prednisolone (10 mg/day), bucillamine (200 mg/day), and intramuscular injections of gold sodium thiomalate $(10 \mathrm{mg} /$ week). During treatment for RA, because his DAS28-CRP score increased over time to 5.9 and because he developed active synovitis of the cervical vertebra, etanercept (50 $\mathrm{mg} /$ week) was added to his medications one month after he quit smoking as per our instructions, but the patient showed no response over the course of one year. The etanercept was then replaced with adalimumab ( $40 \mathrm{mg} / 2$ weeks), but the patient still had no response. Four months after adalimumab was started, his DAS28-CRP was 5.7 and his MMP-3 was $251.9 \mathrm{ng} / \mathrm{mL}$. The patient was therefore switched to TCZ ( $8 \mathrm{mg} / \mathrm{kg}$ monthly), which dramatically improved his symptoms. After switching to TCZ, his DAS28-CRP decreased to less than 2.3 and his MMP-3 decreased to $85.9 \mathrm{ng} / \mathrm{mL}$, but his global assessment ranged from 4 to $5 \mathrm{~cm}$ (Figure 2). Recent radiograms of the involved joints show no erosive progression.

Case 3 is a 48-year-old woman whose smoking index was 560 (20 cigarettes/day $\times 28$ years) $($ Table 1$)$ and had been complaining of pain in both knee joints since 2001 . She was initially treated with a combination of prednisolone (10 mg/day) and methotrexate $(8 \mathrm{mg} /$ week $)$ but did not respond to these medications despite the fact that she was simultaneously undergoing smoking cessation treatment. She was then switched to treatment with adalimumab $(40 \mathrm{mg} / 2$ weeks) due to high disease activity 2 months after she quit smoking but showed no response to the new medication over the course of 1.5 years. At the end of this period, her DAS28-CRP was 3.2 and her MMP-3 was $88.2 \mathrm{ng} / \mathrm{mL}$. The patient was therefore switched to TCZ ( $8 \mathrm{mg} / \mathrm{kg}$ monthly), which dramatically improved her symptoms. After a single drip infusion of TCZ, her DAS28-CRP decreased to 1.8 and her MMP-3 decreased to $59.5 \mathrm{ng} / \mathrm{mL}$ (Figure 3). She has since satisfied the Boolean-based definition for 5 months. The latest radiographic examination of the involved joints showed no progression of bone erosion.

\section{Discussion}

Papadopoulos defined a previous smoker as a person who had stopped smoking for at least one year [5]. Cases 2 and 3 were treated with biologics in less than 3 months after smoking cessation; these two cases could therefore be considered current smokers. For case 1 who had smoked for 20 years, the influence of smoking was assumed to exist although etanercept was initiated 1.5 years after quitting smoking. It is said that even if quitting smoking can be achieved, it takes 


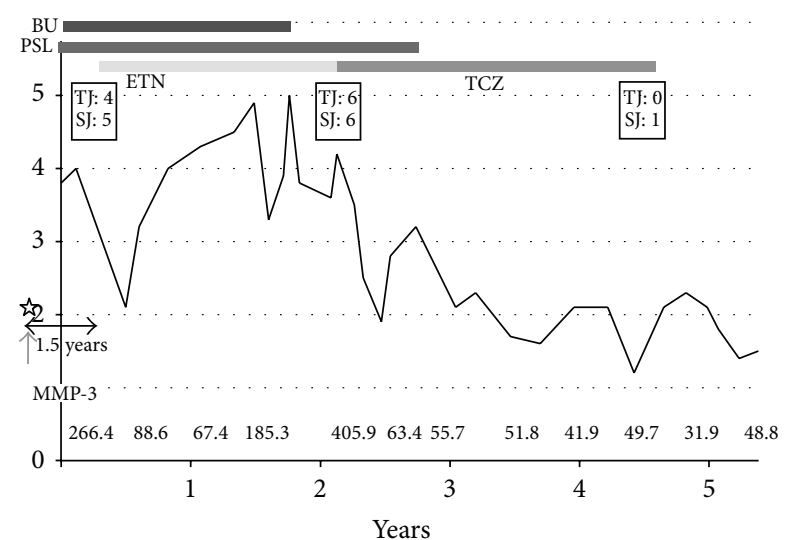

FIGURE 1: Summary of the clinical course of case 1. DAS28-CRP Disease Activity Score assessing 28 joints with C-reactive protein. SASP: salazosulfapyridine, PSL: prednisolone, ETN: etanercept, TCZ: tocilizumab, and MMP-3: matrix metalloproteinase-3. TJ means tender joint counts and SJ means swollen joints counts for the assessment of DAS 28-CRP. The asterisk shows the cessation of smoking. Etanercept was initiated 1.5 years after the cessation of smoking.

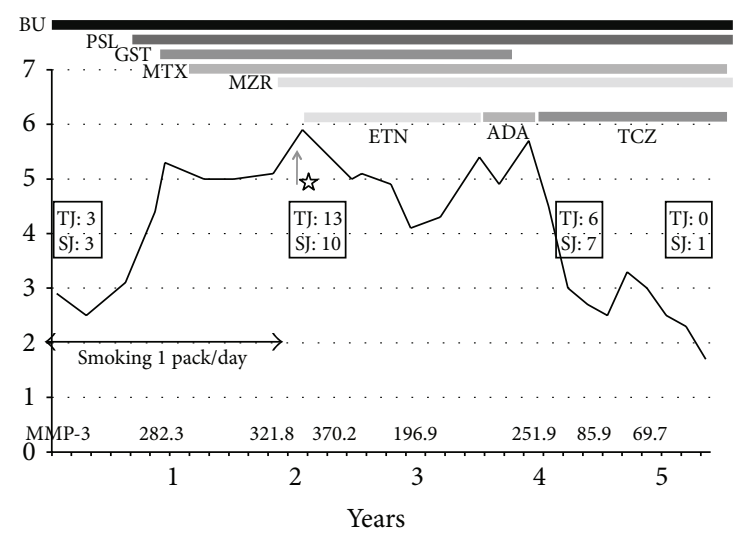

FIGURE 2: Summary of the clinical course of case 2. DAS28CRP Disease Activity Score assessing 28 joints with C-reactive protein. BU: bucillamine, PSL: prednisolone, GST: gold sodium thiomalate, MTX: methotrexate, MZR: mizoribine, ETN: etanercept, ADA: adalimumab, TCZ: tocilizumab, and MMP-3: matrix metalloproteinase-3. The asterisk shows the cessation of smoking. TJ means tender joint counts and SJ means swollen joints counts for the assessment of DAS 28-CRP.

at least 10 years until the influence of smoking disappears from the body [6]. Karlson et al. reported that duration of smoking was associated with a significantly increased risk of developing RA but that smoking intensity (number of cigarettes/day) was unrelated to risk of RA [7].

In case 3, DAS 28-CRP might get better with the use of mizoribine, but the clinical course showed a relapse of arthritis with the use of mizoribine and, after a single drip infusion of TCZ, her DAS28-CRP decreased to 1.8. It is reasonable to assume that TCZ was effective for her RA.

Anti-TNF-alpha agents were reported to have been less effective for the treatment of RA in current and previous smokers [1-4]. The three cases presented herein were

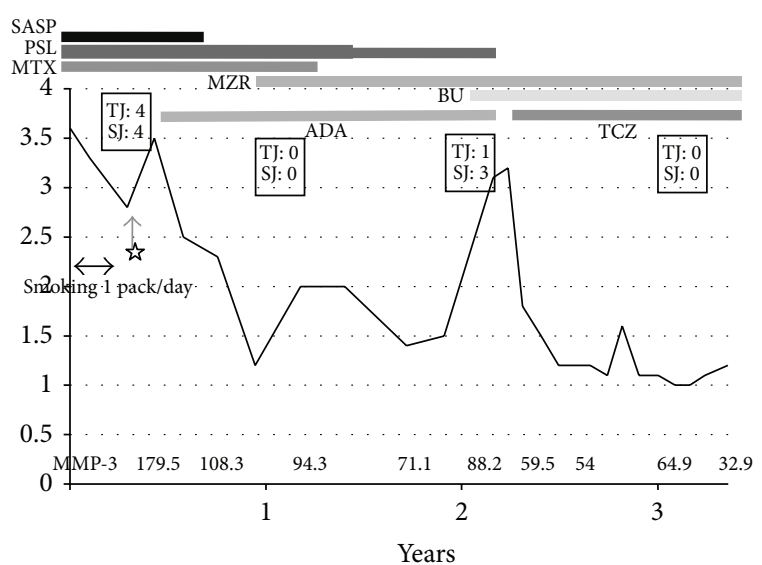

FIGURE 3: Summary of the clinical course of case 3. DAS28-CRP Disease Activity Score assessing 28 joints with C-reactive protein. SASP: salazosulfapyridine, PSL: prednisolone, MTX: methotrexate, MZR: mizoribine, BU: bucillamine, ADA: adalimumab, TCZ: tocilizumab, and MMP-3: matrix metalloproteinase-3. The asterisk shows the cessation of smoking. TJ means tender joint counts and SJ means swollen joints counts for the assessment of DAS 28-CRP.

also refractory to anti-TNF agents, although the patients had stopped smoking before the administration of antiTNF agents. The SAMURAI study demonstrated efficacy in patients with RA treated with TCZ monotherapy [8]. Patients with multidrug refractory adult onset Still's disease (AOSD) were successfully treated with TCZ [9-13].

The relationship between cigarette smoking and the improved response to TCZ probably likely has several explanations. In terms of the relation between smoking and periodontitis, smoking is a major risk factor for periodontitis [1416]. Sites from refractory patient with periodontitis produced significantly more IL-6 [17]. Fibroblasts from periodontal lesions in vitro produce greater amounts of IL-6 and IL8 constitutively than healthy controls [18]. In periodontitis stroma, increased citrullinated protein presence $(80 \%)$ was observed compared with control stroma (33\%). Western blotting with monoclonal (F95) antibody to citrullinated proteins revealed the presence of similar citrullinated proteins in both periodontitis and RA-affected synovial tissue [19]. These three cases did not complain of oral problems. There are some reports on the relationship between IL- 6 in the lungs and smoking. Higher IL-6 and exhaled carbon monoxide (CO) concentrations were found in the exhaled breath condensate of smokers than in that of nonsmokers. In addition, there was a correlation between IL-6 concentrations, number of cigarettes smoked per day, exhaled CO, leukotriene, and lung function [20]. In bronchoalveolar lavage (BAL), statistically greater concentrations of neutrophils, macrophages, IL-1 beta, IL-6, IL-8, and monocyte chemotactic protein1 (MCP-1) were observed among smokers compared with nonsmokers [21]. Smoking increases peptidylarginine deiminase 2 enzyme expression in the human lungs and increases citrullination in BAL cells [22]. Snelgrove reported that cigarette smoke selectively inhibited leukotriene $\mathrm{A}(4)$ hydrolase aminopeptidase activity, which led to the accumulation 
of the neutrophil chemoattractant proline-glycine-proline and neutrophils, and made inflammation become chronic such as chronic obstructive pulmonary disease (COPD) and cystic fibrosis [23]. Cigarette smoke induces proinflammatory cytokines and chemokines, including IL-1 beta, and IL-6 from synovial fibroblast-like cells (SFCs) [24]. And blood leukocytes, platelets, C-reactive protein (CRP), and fibrinogen were reported to be significantly high in smokers [25]. Mean platelet volume increased significantly with acute exposure to smoking [26]. IL-6 stimulates thrombopoiesis through thrombopoietin [27], and IL-6 activates platelets [28]. Boilard et al. surveyed the capacity of collagen-stimulated human platelet microparticles (MPs) to elicit a range of cytokines and chemokines from fibroblast-like synoviocytes (FLSs) and observed prominent production of the broadly inflammatory cytokine IL- 6 and the neutrophil chemoattractant IL- 8 without production of TNF alpha [29]. Therefore, the positive feedback of IL-6 through fibroblast-like synoviocytes and platelets is formed in the human body. In this case report, cases 1 and 3 showed elevation of platelet count.

Smoking is an established risk factor of RA and may cause prominent production of cytokines especially IL-6 (as described above). An IL-6 blockade might be suitable for treating these 3 cases. But this is a case report; however, further study of a large series of cases is required to determine the efficacy of an IL-6 blockade for patients with RA who smoke.

\section{Conflict of Interests}

The author declares that there is no conflict of interests regarding the publication of this paper.

\section{References}

[1] D. L. Mattey, A. Brownfield, and P. T. Dawes, "Relationship between pack-year history of smoking and response to tumor necrosis factor antagonists in patients with rheumatoid arthritis," Journal of Rheumatology, vol. 36, no. 6, pp. 1180-1187, 2009.

[2] A. Abhishek, S. Butt, K. Gadsby, W. Zhang, and C. M. Deighton, "Anti-TNF- $\alpha$ agents are less effective for the treatment of rheumatoid arthritis in current smokers," Journal of Clinical Rheumatology, vol. 16, no. 1, pp. 15-18, 2010.

[3] S. Saevarsdottir, S. Wedrén, M. Seddighzadeh et al., " Patients with early rheumatoid arthritis who smoke are less likely to respond to treatment with methotrexate and tumor necrosis factor inhibitors: observations from the epidemiological investigation of rheumatoid arthritis and the Swedish rheumatology register cohorts," Arthritis and Rheumatism, vol. 63, no. 1, pp. 26-36, 2011.

[4] M. K. Söderlin, I. F. Petersson, and P. Geborek, "The effect of smoking on response and drug survival in rheumatoid arthritis patients treated with their first anti-TNF drug," Scandinavian Journal of Rheumatology, vol. 41, no. 1, pp. 1-9, 2012.

[5] N. G. Papadopoulos, Y. Alamanos, P. V. Voulgari, E. K. Epagelis, N. Tsifetaki, and A. A. Drosos, "Does cigarette smoking influence disease expression, activity and severity in early rheumatoid arthritis patients?" Clinical and Experimental Rheumatology, vol. 23, no. 6, pp. 861-866, 2005.

[6] S. Musich, S. D. Faruzzi, C. Lu, T. McDonald, D. Hirschland, and D. W. Edington, "Pattern of medical charges after quitting smoking among those with and without arthritis, allergies, or back pain," The American Journal of Health Promotion, vol. 18, no. 2, pp. 133-142, 2003.

[7] E. W. Karlson, I. M. Lee, N. R. Cook, J. E. Manson, J. E. Buring, and C. H. Hennekens, "A retrospective cohort study of cigarette smoking and risk of rheumatoid arthritis in female health professionals," Arthritis \& Rheumatism, vol. 42, no. 5, pp. 910-917, 1999.

[8] N. Nishimoto, J. Hashimoto, N. Miyasaka et al., "Study of active controlled monotherapy used for rheumatoid arthritis, an IL6 inhibitor (SAMURAI): evidence of clinical and radiographic benefit from an $\mathrm{x}$ ray reader-blinded randomised controlled trial of tocilizumab," Annals of the Rheumatic Diseases, vol. 66, no. 9, pp. 1162-1167, 2007.

[9] M. de Bandt and B. Saint-Marcoux, "Tocilizumab for multirefractory adult-onset Still's disease," Annals of the Rheumatic Diseases, vol. 68, no. 1, pp. 153-154, 2009.

[10] K. Matsumoto, T. Nagashima, S. Takatori et al., "Glucocorticoid and cyclosporine refractory adult onset Still's disease successfully treated with tocilizumab," Clinical Rheumatology, vol. 28, no. 4, pp. 485-487, 2009.

[11] M. Yoshimura, J. Makiyama, T. Koga et al., "Successful treatment with tocilizumab in a patient with refractory adult-onset Still's disease (AOSD)," Clinical and Experimental Rheumatology, vol. 28, no. 1, pp. 141-142, 2010.

[12] K. Perdan-Pirkmajer, S. Praprotnik, and M. Tomšič, "A case of refractory adult-onset Still's disease successfully controlled with tocilizumab and a review of the literature," Clinical Rheumatology, vol. 29, no. 12, pp. 1465-1467, 2010.

[13] J. Rech, M. Ronneberger, M. Englbrecht et al., "Successful treatment of adult-onset Still's disease refractory to TNF and IL1 blockade by IL-6 receptor blockade," Annals of the Rheumatic Diseases, vol. 70, no. 2, pp. 390-392, 2011.

[14] S. L. Tomar and S. Asma, "Smoking-attributable periodontitis in the United States: findings from NHANES III," Journal of Periodontology, vol. 71, no. 5, pp. 743-751, 2000.

[15] B. H. Mullally, "The influence of tobacco smoking on the onset of periodontitis in young persons," Tobacco Induced Diseases, vol. 15, no. 2, pp. 53-65, 2004.

[16] Y. Yamamoto, N. Nishida, M. Tanaka et al., "Association between passive and active smoking evaluated by salivary cotinine and periodontitis," Journal of Clinical Periodontology, vol. 32, no. 10, pp. 1041-1046, 2005.

[17] R. A. Reinhardt, M. P. Masada, W. B. Kaldahl et al., "Gingival fluid IL-1 and IL-6 levels in refractory periodontitis," Journal of Clinical Periodontology, vol. 20, no. 3, pp. 225-231, 1993.

[18] A. I. Dongari-Bagtzoglou and J. L. Ebersole, "Increased presence of interleukin-6 (IL-6) and IL-8 secreting fibroblast subpopulations in adult periodontitis," Journal of Periodontology, vol. 69, no. 8, pp. 899-910, 1998.

[19] W. Nesse, J. Westra, J. E. van der Wal et al., “The periodontium of periodontitis patients contains citrullinated proteins which may play a role in ACPA (anti-citrullinated protein antibody) formation," Journal of Clinical Periodontology, vol. 39, no. 7, pp. 599-607, 2012.

[20] G. E. Carpagnano, S. A. Kharitonov, M. P. Foschino-Barbaro, O. Resta, E. Gramiccioni, and P. J. Barnes, "Increase inflammatory markers in the exhaled breath condensate of cigarette smokers," The European Respiratory Journal, vol. 21, no. 4, pp. 589-593, 2003. 
[21] W. G. Kuschner, A. D’Alessandro, H. Wong, and P. D. Blanc, "Dose-dependent cigarette smoking-related inflammatory responses in healthy adults," European Respiratory Journal, vol. 9, no. 10, pp. 1989-1994, 1996.

[22] D. Makrygiannakis, M. Hermansson, A.-K. Ulfgren et al., "Smoking increases peptidylarginine deiminase 2 enzyme expression in human lungs and increases citrullination in BAL cells," Annals of the Rheumatic Diseases, vol. 67, no. 10, pp. 14881492, 2008.

[23] R. J. Snelgrove, P. L. Jackson, M. T. Hardison et al., "A critical role for LTA4H in limiting chronic pulmonary neutrophilic inflammation,” Science, vol. 330, no. 6000, pp. 90-94, 2010.

[24] M. Shizu, Y. Itoh, R. Sunahara et al., "Cigarette smoke condensate upregulates the gene and protein expression of proinflammatory cytokines in human fibroblast-like synoviocyte line," Journal of Interferon and Cytokine Research, vol. 28, no. 8, pp. 509-521, 2007.

[25] H. Yasue, N. Hirai, Y. Mizuno et al., "Low-grade inflammation, thrombogenicity, and atherogenic lipid profile in cigarette smokers," Circulation Journal, vol. 70, no. 1, pp. 8-13, 2006.

[26] M. Yarlioglues, I. Ardic, O. Dogdu et al., "The acute effects of passive smoking on mean platelet volume in healthy volunteers," Angiology, vol. 63, no. 5, pp. 353-357, 2012.

[27] A. Kaser, G. Brandacher, W. Steurer et al., "Interleukin-6 stimulates thrombopoiesis through thrombopoietin: role in inflammatory thrombocytosis," Blood, vol. 98, no. 9, pp. 27202725, 2001.

[28] L. Oleksowicz, Z. Mrowiec, D. Zuckerman, R. Isaacs, J. Dutcher, and E. Puszkin, "Platelet activation induced by interleukin6: evidence for a mechanism involving arachidonic acid metabolism," Thrombosis and Haemostasis, vol. 72, no. 2, pp. 302-308, 1994.

[29] E. Boilard, P. A. Nigrovic, K. Larabee et al., "Platelets amplify inflammation in arthritis via collagen-dependent microparticle production," Science, vol. 327, no. 5965, pp. 580-583, 2010. 


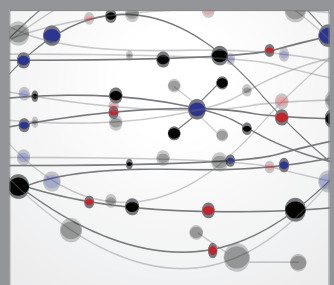

The Scientific World Journal
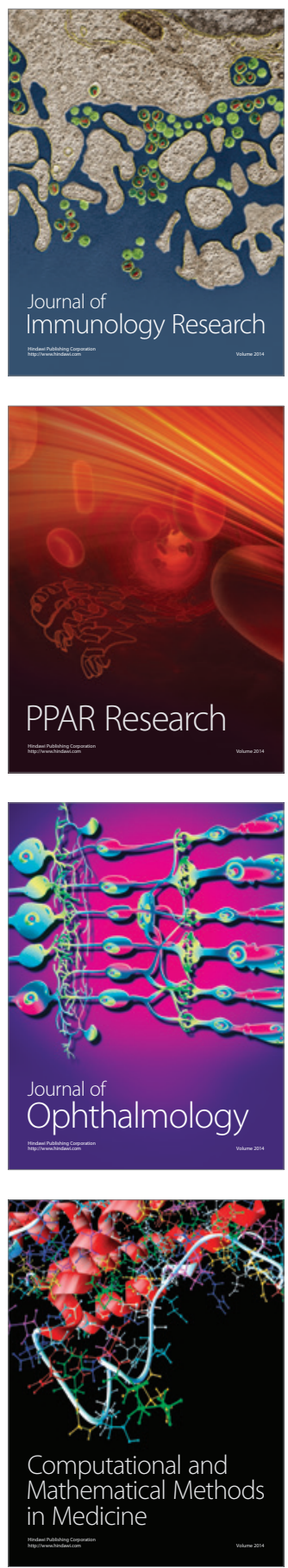

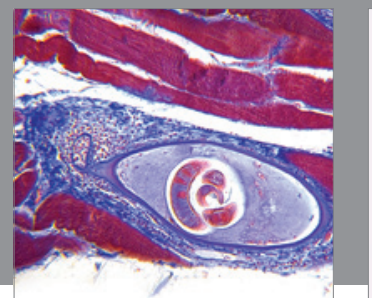

Gastroenterology

Research and Practice
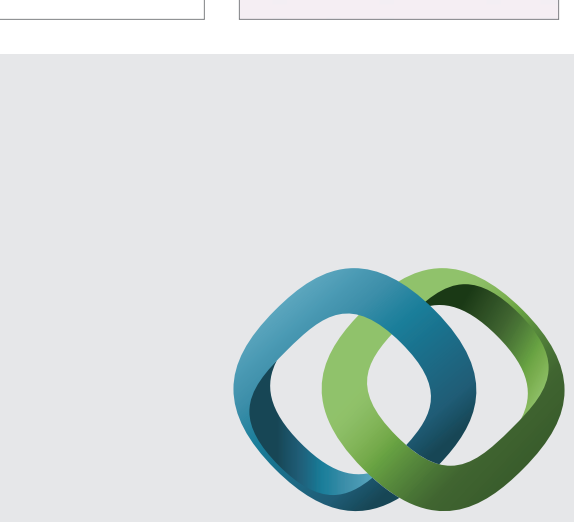

\section{Hindawi}

Submit your manuscripts at

http://www.hindawi.com
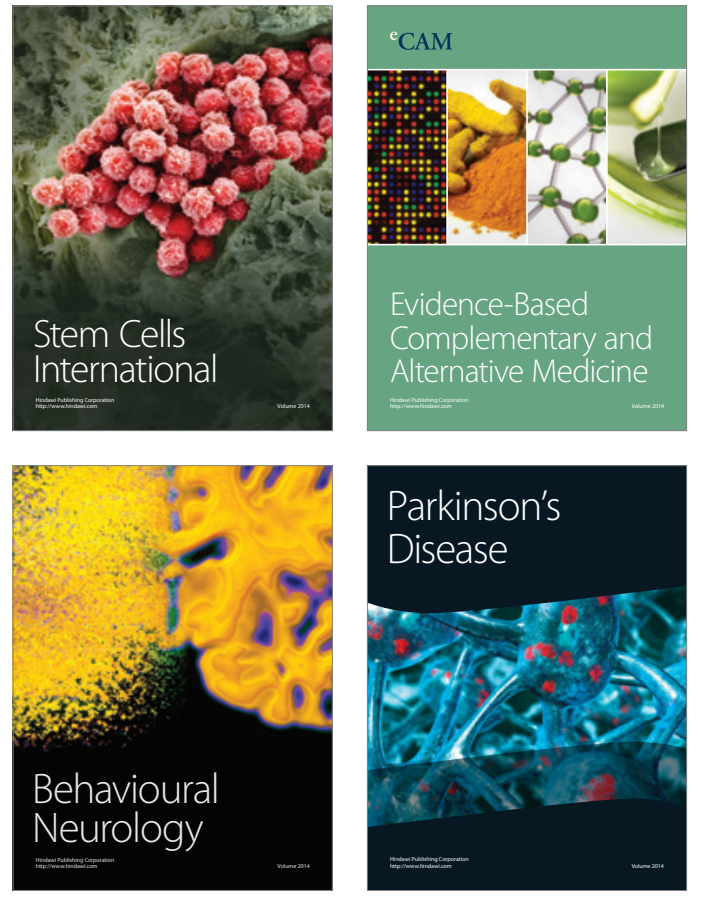
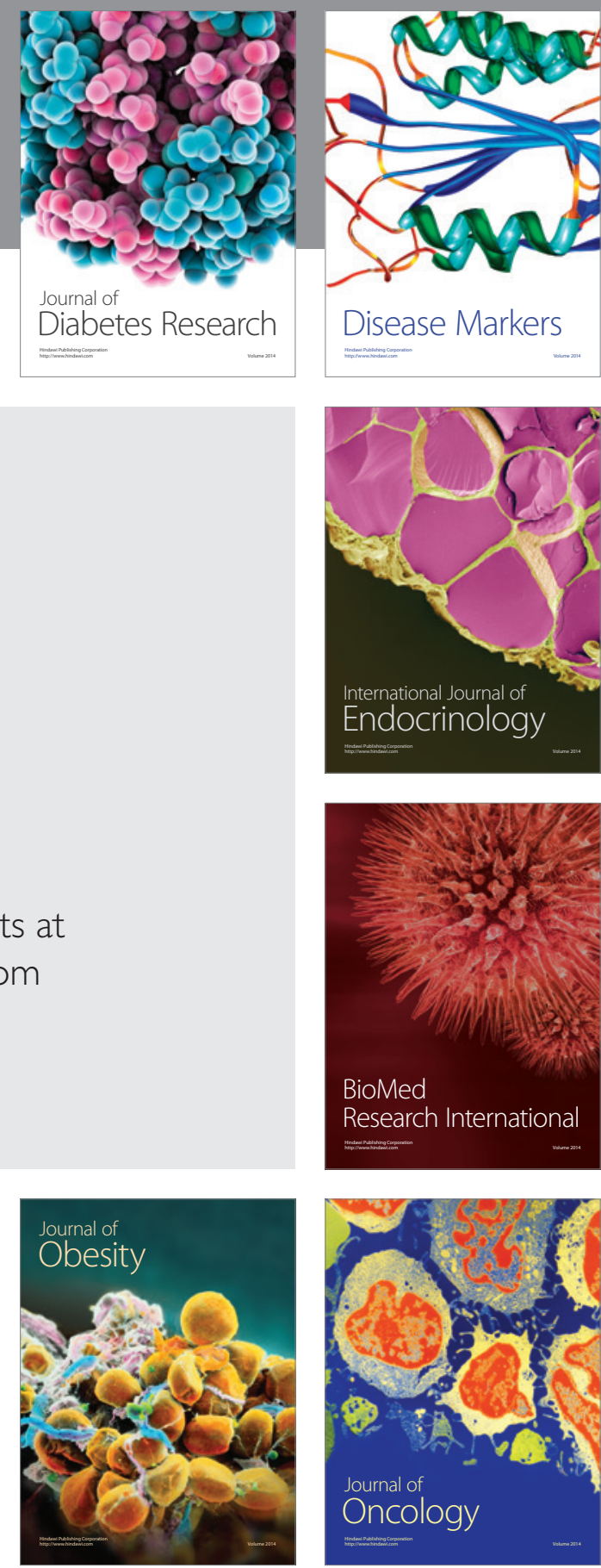

Disease Markers
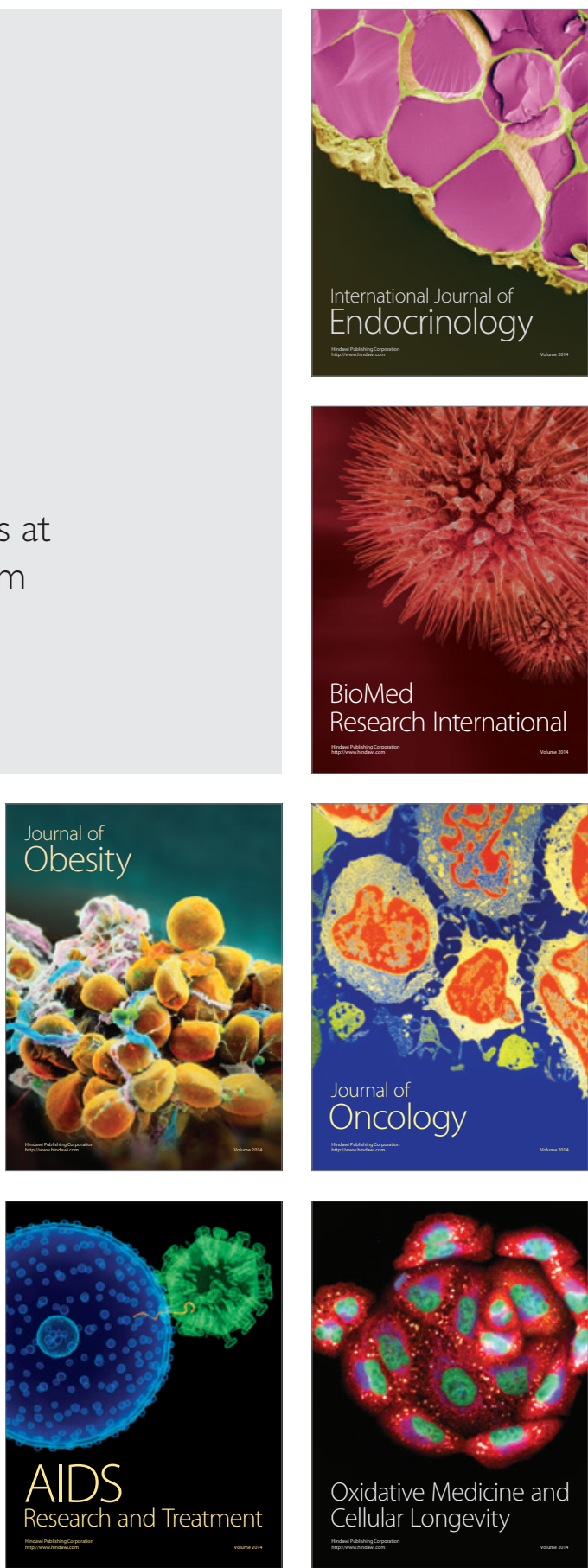